\section{Wiregrass Propagation}

\author{
at the Andrews \\ $N$ ursery in Florida
}

Tim Pit t man and

Robert P Karrfalt

KEYWORDS: container nursery, seed collection

NOMEN CLATURE: ITIS (1998)

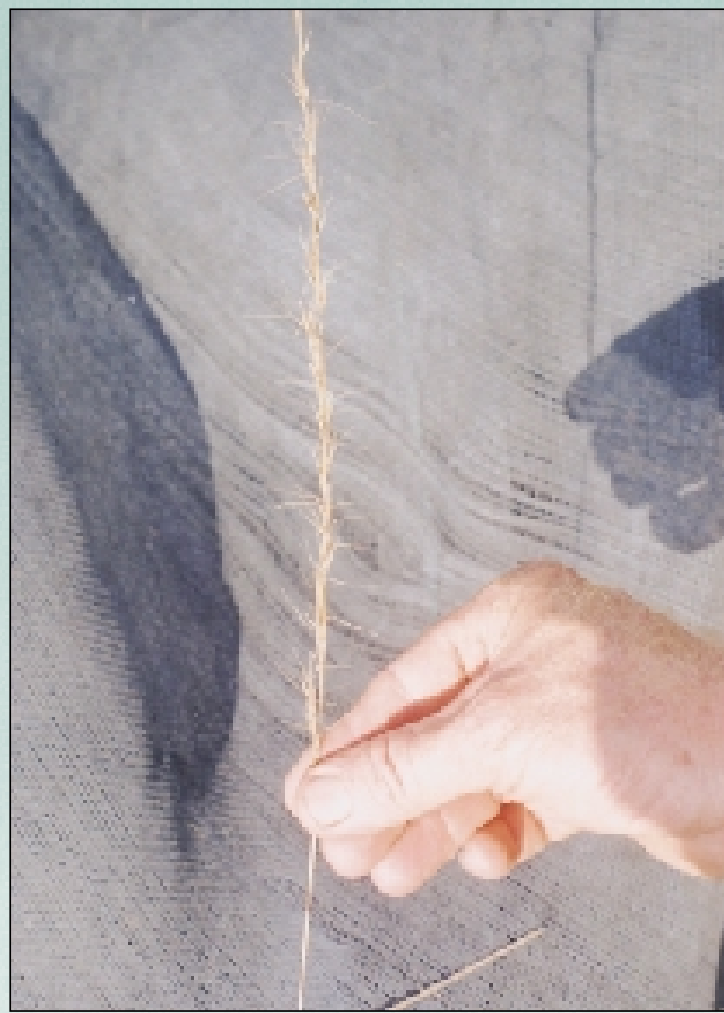

Figure 1 - A single stalk of wiregrass. For our preharvest seed quality survey, we sample 100 stalks from 100 plants per site.
W regrass (Aristida beyri chiana Trin. \& Rupr.

[Poaceae]) is a major component of the longleaf pine ecosystem. This species was formerly named Aristida stricta. H owever, A. stricta $M$ ichx. (Poaceae) is now considered confined to $\mathrm{N}$ orth Carolina and northern tier counties of South Carolina, while $A$. beyrichiana occurs from southern South Carolina through $\mathrm{G}$ eorgia to Florida and west to M ississippi (Peet 1993).

In the late 1980s, water management districts in Florida needed wiregrass plants for site restoration. The demand was high, but stock was unavailable. Vegetative propagation from the wild was too expensive and counterproductive because it required removal or at least disruption of plants already established in the wild. D evelopment of nursery propagation techniques from seeds was, therefore, undertaken. Bareroot production could produce plants but was an inefficient use of bed space, and plants were difficult to handle because of the widely spreading root systems. Containers were later found to be much more workable.

\section{Seed crops}

Seed crops are unpredictable and hard to find. Although seeds may appear to be present, they often do not germinate. $C$ auses for the lack of germination are not well known but almost surely involve insect feeding, fungi, and environmental factors. One trend that appears to hold is that the most consistent crops are found on sites that have had summer burns on 3-y cycles for at least $10 \mathrm{y}$. As a result of the unpredictable germination, a great deal of sampling in the field is necessary to find a crop worth collecting. $O$ ur technique is to walk many hectares at many sites, making numerous random samples per site. A sample is composed of 100 individual stalks (Figure 1) cut from 100 individual plants spread over at least 4 to 5 stops per site. This composite sample for each site is then taken to the nursery where 20 stalks are drawn at random for a viability test. Seeds are striped from the stalk by pulling the stalk, base end first, through pinched fingers. We immediately place the seeds into a petri dish containing a cross-linked polymer used for treating plant roots at transplanting. The polymer is moistened with water to form a gel. The fine grade of the polymer is preferred as it makes a firmer gel. O ne container of polymer is used for a number of years to help keep the evaluations uniform from year to year. Germination is done under natural light at room temperature in the nursery office. Germination is complete in 12 to $30 \mathrm{~d}$ at ambient conditions 
The number of lines was increased from 4 lines per row to 16 and 17 per row. Bristles were staggered from row to row to give a brushing effect. Two rows of 16 and 2 rows of 17 bristles make up the head. Bristles are held in place by pop rivets. A hook was used to hold the rivet in the hole (Figure 4) until the filament was in place.

We collect seeds from mid N ovember to mid D ecember. Collection intervals depend on weather- harvesting as a tropical inversion approaches is not a good idea. Low humidity days $(<75 \%)$ are best because the awns open, exposing seeds and allowing seeds to fall freely without clinging to plant stalks. Seeds will not shatter from the plant even when humidity is germination results in 6 to $12 \mathrm{~d}$. light is required but some light helps make the seedlings easier to see because they have chlorophyll initiation and are green. Those sites that produced viable seeds are revisited for seed collection.

\section{Collection}

Because wiregrass sites are ecologically sensitive, wheeled machinery is prohibited. H owever, hand collection alone is not practical. We tested a prairie seed striper (Figure 3) purchased from Prairie $\mathrm{H}$ abitats in Argyle, $\mathrm{M}$ anitoba, $\mathrm{C}$ anada, and found it to be a good device for rapidly collecting seeds. This device is a string trimmer motor and drive shaft connected to a rotating shaft that has monofilament lines coming out of it in staggered rows. As the shaft rotates it strips the seeds from the plant into the collection basket that is mounted behind it. The filaments on the sweeper head supplied by the vendor were found to be too stiff for wiregrass. Instead of stripping the seeds, they cut the entire stalk. W ith the assistance of Frank $\mathrm{O}$ steen of Port W hite, Florida, the head was redesigned and now uses 0.065 gauge "Starline" string trimmer line. This line is star shaped in cross section and more pliable than that originally used.

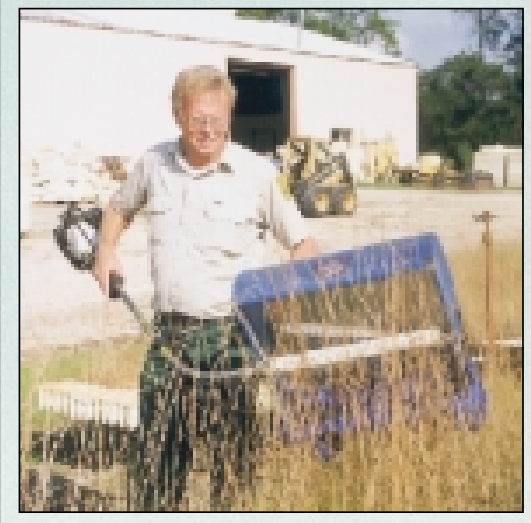

Figure 3 - Prairie seed stripper used for seed collection on wiregrass sites.

high. H owever, animals walking through the grass will dislodge seeds. Seed yields on dry days are twice as high as those on humid days. We recommend collecting after 09:00 AM.

Seeds should be held in barrels at ambient temperatures for 5 mo as viability increases during this period (H ermann 1999) and used within 8 mo. Beyond $8 \mathrm{mo}$, viability drops rapidly. Long-term storage studies are under way to determine methods for storing beyond 6 mo so that a seed bank can be developed and dependance on annual collection avoided. In February or M arch, germination tests are made on collected seeds. These tests are made on 2 samples containing 100 seeds each. Seeds are individually pulled from the barrel and placed on the gel in plastic boxes $(10.2 \times 15.2 \mathrm{~cm}$ [ $4 X 6$ in]). Germination rates range from $17 \%$ to $30 \%$. We weigh seeds to determine the number of seeds per gram by counting out replicates of 100 seeds and placing them on a balance until $1.0 \mathrm{~g}$ of seeds is obtained. The range of seed weights has been from 1400 to 2500 seeds per g $(39,200$ to 70,000 per oz). We estimate purity.

\section{Propagation}

Seedlings are grown in Ropak MultiPot \#3-96 containers that have a volume of $98 \mathrm{ml}\left(6 \mathrm{in}^{3}\right)$, are $12 \mathrm{~cm}$ ( 5 in) deep, and have a density of 441 cavities per $\mathrm{m}^{2}\left(41 / \mathrm{ft}^{2}\right)$. We fill containers with Vergro Poly M ix B (Verlite Corp, Tampa, Florida). The mix contains 5:3:2 peat moss:polystyrene beads:coarse vermiculite and controlled release 0 smocote plus minors $\left(17 \mathrm{~N}: 6 \mathrm{P}_{2} \mathrm{O}_{5}: 10 \mathrm{~K}_{2} \mathrm{O} ; 8\right.$ to 9 $\mathrm{mo}$ at $\left.21^{\circ} \mathrm{C}\left[70^{\circ} \mathrm{F}\right]\right)$ added at 1.54 $\mathrm{kg} / \mathrm{m}^{3}\left[4.5 \mathrm{lb} / \mathrm{yd}^{3}\right]$. Comparable mixes would also likely work. Sowing must be done before hot weather arrives and after danger of frost is fully past- target sowing date in Chiefland, Florida, is 1 A pril. Seeds are mixed well with medium or course grade vermiculite in a ribbon mixing machine at a rate of 150 to $200 \mathrm{~g}$ (5.4 to $7.1 \mathrm{oz}$ ) of seeds per $0.12 \mathrm{~m}^{3}\left(4 \mathrm{ft}^{3}\right)$ of vermiculite. The vermiculite and growing medium is used just as it comes from the bag. Adding water is not done because this causes seeds to stick in the mixing machine. We spread the mix on filled, pressed M ulti-Pots at a depth of 6 to $12 \mathrm{~mm}(0.25$ to 0.5 in). Trays are watered and placed in an outdoor growing area. Shade cloth is spread over the trays and weighed down with lumber, otherwise hard rain storms can wash all the vermiculite-seed mix out of the containers. We allow seeds to germinate and seedlings to grow 
through the shade cloth. Some 6 to $15 d$ after sowing, seedlings will have grown about $25 \mathrm{~mm}$ (1 in) tall and the shade cloth should be removed because taller plants will begin tillering and not slide freely through the cloth when it is removed. We irrigate the crop daily (because of the well-drained mix) with an overhead fixed system, receiving 2.5 to $4 \mathrm{~cm}$ (1 to 1.5 in) of irrigation water per container. Seedlings are ready for planting in $3 \mathrm{mo}$, although depending on planting site, seedlings may remain at the nursery for up to $12 \mathrm{mo}$ (Figure 5). M ost top growth is done after $5 \mathrm{mo}$, at which time most plants begin flowering. Unfortunately, seeds collected from nursery

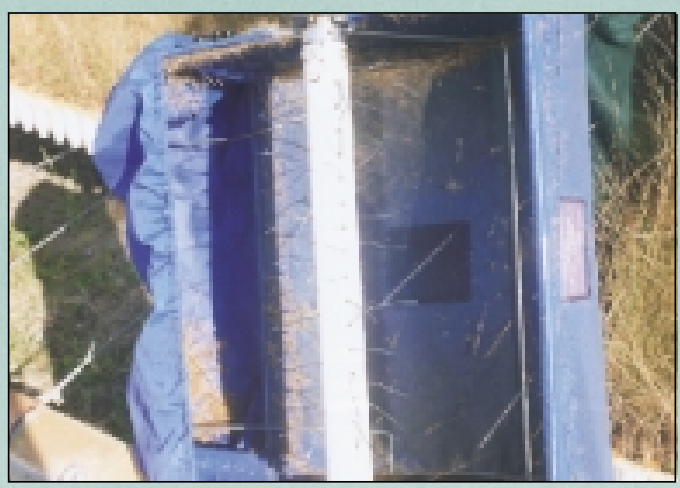
Figure 4 - Closeup of prairie seed stripper head that was modified by using more and softer filaments on the rotating central shaft. plants have very low

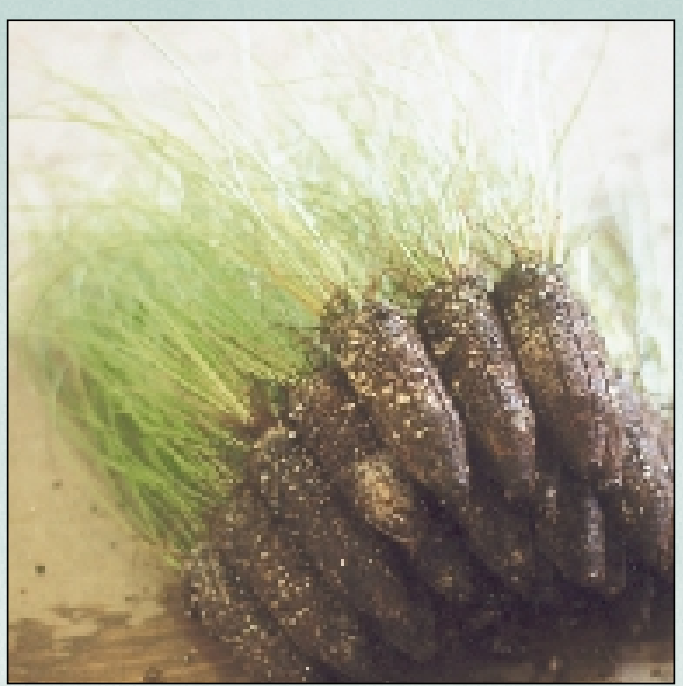

Figure 5 - W iregrass seedlings pulled from the containers and ready for shipping to planting site.

viability. We extract seedlings from containers before shipment to planting sites. Plants required to be in boxes for more than $2 \mathrm{~d}$ are refrigerated. Seedlings can be stored in refrigerators for a month. Seedling production cost (US\$170 per 1000 plants) is less than $15 \%$ of the cost of vegetatively multiplied plants collected in the wild.

\section{Ref erences}

Hermann SM. 1999. Personal communication. Tallahassee (FL): Tall Timbers Research Station.

[ITIS] Integrated Taxonomic Information System. 1998. Biological $\mathrm{N}$ ames, Version 4.0 (on-line database). URL: http:/ / www. itis.usda.gov/ plantproj/ itis/ itis_query.html (updated 15 December 1998).

Peet RK. 1993. A taxonomic study of A ristida stricta and $A$. beyrichiana. Rhodora 95(881):25- 37 .

\section{Author Information}

Tim Pittman

Container N ursery Supervisor

Andrews Nursery

Florida Division of Forestry

PO Drawer 849

Chiefland, FL 32644

Robert P Karrfalt

Director

National Tree Seed Laboratory

USDA Forest Service

Rt 1 Box 182-B

Dry Branch, GA 31020

rkarrfalt/ r8@ fs.fed.us 